\title{
Effects of Demographic Factors on the Psychosocial Challenges of Adolescents in Lagos State. Implications for Counselling
}

\author{
Ayodeji Badejo, Lamidi Salimot Bola \\ Department of Educational Foundations and Counselling, Lagos State University, Ojo, Nigeria \\ Email: lamidisalmat@gmail.com
}

How to cite this paper: Badejo, A., \& Bola, L. S. (2021). Effects of Demographic Factors on the Psychosocial Challenges of Adolescents in Lagos State. Implications for Counselling. Psychology, 12, 59-67. https://doi.org/10.4236/psych.2021.121004

Received: November 25, 2020

Accepted: January 10, 2021

Published: January 13, 2021

Copyright $\odot 2021$ by author(s) and Scientific Research Publishing Inc. This work is licensed under the Creative Commons Attribution International License (CC BY 4.0).

http://creativecommons.org/licenses/by/4.0/

\begin{abstract}
This study examined the impact of demographic factors on the psychosocial challenges of adolescents in Lagos state and putting into consideration their implications for counselling. Three research hypotheses were made to guide the study. The sample consisted of one hundred (100) senior secondary school students selected from Badagry local government area of Lagos state. A 40 item self-developed questionnaire was designed for data collection. The study adopted a descriptive design to seek information from the respondents. Analysis of data was achieved using the descriptive statistics and Analysis of Variance at the level of significance of 0.05 . The result of the findings showed that there is a significant effect of demographic factors on the psychosocial challenges of adolescents. Based on the findings, conclusions were made and some implications for counselling were also made.
\end{abstract}

\section{Keywords}

Adolescents, Psychosocial Challenges, Secondary Schools, Demographic Factors

\section{Introduction}

Over the years, as adolescents undergo the period of transition, they are being faced with several challenges which seems to have negative impact on their psychosocial development. Also, when proper care and attention are not showered on these adolescents, it may heighten their problems, thereby leading to psychosocial challenges in them. Psychosocial challenges are the problems and vices adolescents encounter which may include behavioural problem, social, educational as well as emotional problem. Adolescence is an age of change; it is a pe- 
riod of evolution from immaturity of childhood to maturity of adulthood. According to World Health Organization (2017), Adolescence is the period of age ranging from 10 years to 19 years, is one of the serious transition in the lifecycle that occurs after childhood and before adulthood and is considered by a tremendous pace in growth and change that is second only to that of infancy. It is a phase where several changes occur in individual and these changes may include, the biological changes, cognitive changes, emotional changes as well as social changes. As these changes occur, it tends to affect the psychosocial development of adolescent and that is why Stanley Hall (1904) denoted the period as the period of storm and stress. As adolescents go through numerous changes, they tend to be faced with multiple challenges, and these challenges if not well attended to may be threatening to the overall development of the adolescents. Adolescence period is the perilous times for developing good mental health (Kessler, Berglund, Demler, Jin, Merikangas, \& Walters, 2005). Erkson believed that each phase of life is denoted by a specific struggle between challenging predispositions. Only if individuals overcome each of these hurdles successfully, they can develop in a regular and healthful manner. During this phase, adolescents must incorporate various roles into a consistent self-personality. If they fail to do so, they may encounter misunderstanding about who they are which may lead to psychosocial dysfunction. Psychosocial challenges have been defined by various researchers and it can be deduced that psychosocial challenges are problems or issues that adolescents are confronted with which affect their overall wellbeing.

For adolescents to function well in any given society, the atmosphere must be filled with attention, love, and understanding. In the contemporary world, many adolescents are faced with psychosocial issues because of how there were trained and the exposure they were given. Apart from that, the family type of adolescents also determines the psychosocial competence of adolescents (Ajidaun, 2011). The home being the first agent of socialization needs proper nurturing for it to accomplish its duty to the members. Adolescents seem to benefit greatly when one or both parents are highly involved in their nurture. The act of fostering the young ones to the stage of adolescence is a great job for every parent to achieve. Apart from upbringing, lack of warmth and nurture from the parents may affect the advancement of adolescents in terms of their self-concept and self-control. That is, an atmosphere filled with unconditional love, empathy, and good health is expected to enhance the wellbeing of adolescents.

According to Conger and Chao (1996), adolescents from divorced homes are more likely than adolescents from intact homes to have a lesser amount of intimate relationship with their parents. Sometimes they also fall out of school because of a lack of concentration and may also be sexually active at a tender age because there may not be proper monitoring of their behaviour. Emotional and behavioural difficulties may arise from the parental conflict before divorce and or after divorce, as well as from the split-up. In the view of Young (1997), a smooth functioning family can provide support to an adolescent during period of stress and crisis. Adolescents from divorced or single-parent families tend to 
do poorer in school and get into troubles with the school authorities more than adolescents from two parents' homes, perhaps because single parent find it tough to monitor their children on top of their other tasks.

Single-gender parent seems to be a determinant to the adolescent psychosocial problem. Lack of a father in homes may lead to behaviour problems and psychosocial maladjustment. Throughout the teen years, the father frequently assumes the main duty for disciplining male adolescents who at times exhibit more rebellious and delinquent behaviour. Some studies show that males are more predisposed to psychosocial problems than their female counterparts. According to Younger, Warrington \& Williams (2010), problems of social recognition and integration among peers, aggressive behaviour are more common in adolescent boys than the adolescent girls.

Adolescents and psychosocial Problems cannot be isolated from one another. This is because adolescent's period of transition encompasses so many changes and as these changes occur, if proper care, love, attention, and understanding are not showered, the adolescents may end up displaying some psychosocial problems such as social problems, behavioural problems, emotional problems as well as educational problems which eventually disrupt their psychosocial competence and in the long run lead to issues of delinquency, armed robbery, hooliganism, violence, school dropout, violation of rules and regulations, terrorism and a host of them. Adolescents are susceptible to psychosocial dysfunction when they suffer from physical damages psychological distress, or major alterations in their environments especially in the absence of a strong support system (Pratt, 2003).

Considering the factors responsible for the psychosocial problems in adolescents, several pieces of research have been conducted within and outside the country on issues relating to Adolescents' psychosocial problems and their predisposing factors. For instance, Bista, Thapa, Sapkota, Singh, and Pokharel (2016), identified family type as a significant factor for psychosocial dysfunction among adolescents. It also identified that adolescents living with a single parent were more disposed to psychosocial problems than those from both parents. According to Bingham (2006), it is observed that male has a greater number of problems than female. Besides, Kekkonen, Kivimaki, Valtonen, Tolmunen, Lehto, Hintikk \& Laukkanen (2015), discovered that among male adolescents, a fatherly occupation reported as not known associated with an increased number of primary health care visits when compared to adolescents with fathers who were white-collar workers. It also showed that adolescent females were more often frequent users of primary health care (due to psychosocial problems) than their male counterparts. Part of the novelties of this work is basically to investigate the effect of demographic factors on the psychosocial development of every adolescent going through a tough transition to adulthood and it is expected that it has a positive impact on curbing adolescents' psychosocial challenges.

\subsection{Purpose of the Study}

The purpose of the study is to establish the effect of demographic factors on the 
psychosocial challenges of adolescents in Lagos State.

\subsection{Research Hypotheses}

1) There is no significant effect of gender on the psychosocial challenges of adolescents in Lagos State.

2) There is no significant effect of age on the psychosocial challenges of adolescents in Lagos State.

3) There is no significant effect of family type on the psychosocial challenges of adolescents in Lagos State.

\section{Methodology}

The research design that was adopted is a descriptive survey design. The population of the study consists of all secondary school adolescents in Lagos State. The sample for the study consists of 100 secondary school adolescents. The sampling technique that was adopted is Simple random sampling where every member has an equal chance of being selected.

The instrument (questionnaire) used was developed by the researchers titled Adolescents Psychosocial Problem Inventory (APPI). The questionnaire contains five (5) sections. Section A consists of Bio-data information of the respondents, sections B, C, D, and E consist of items on the psychosocial problems of adolescents.

The instrument was validated by experts in psychometrics and the reliability of the instrument was ascertained through Cronbach Alpha with the reliability coefficient of 0.81 which indicates that the instrument is reliable for use.

This study employed both descriptive and inferential statistics to analyze the data collected. The descriptive statics was used to describe the respondent's biodata. The hypotheses generated were analyzed using ANOVA and t-test. All the hypotheses were tested at 0.05 level of significance.

\section{Results}

The sections present the results of the findings. The presentation follows the order in which the research hypotheses were presented. The level of significance was set up at $<0.05$.

\section{Descriptive statistics}

From Table 1, 60\% of the respondents which correspond to 60 students are between ages 14 and $16,30 \%$ of the respondents which correspond to $30 \mathrm{stu}-$ dents are between ages 17 and 18 while $10 \%$ of the respondents which correspond to 10 students are above 18 years. This showed that more respondents are between ages 14 to 16 years.

From Table 2, 70\% of the respondents which correspond to 70 students are male while only $30 \%$ of the respondents which correspond to 30 students are female. This showed that more male students participated in the study.

From Table 3, 40\% of the respondents which correspond to 40 students lived 
Table 1. Age.

\begin{tabular}{ccccc}
\hline & Frequency & Percent & Cumulative Percent \\
\hline \multirow{3}{*}{ Valid } & $14-16$ & 60 & 60.0 & 60.0 \\
& $17-18$ & 30 & 30.0 & 90.0 \\
& above 18 & 10 & 10.0 & 100.0 \\
\hline & Total & 100 & 100.0 & \\
\hline
\end{tabular}

Table 2. Gender.

\begin{tabular}{ccccc}
\hline & & Frequency & Percent & Cumulative Percent \\
\hline \multirow{3}{*}{ Valid } & Male & 70 & 70.0 & 70.0 \\
& Female & 30 & 30.0 & 100.0 \\
& $\mathrm{~S}$ & 100 & 100.0 & \\
\hline
\end{tabular}

Table 3. Family type.

\begin{tabular}{ccccc}
\hline & & Frequency & Percent & Cumulative Percent \\
\hline \multirow{3}{*}{ Valid } & Both Parents & 40 & 40.0 & 40.0 \\
& Single Parent & 30 & 30.0 & 70.0 \\
& Non-Parent & 30 & 30.0 & 100.0 \\
& Total & 100 & 100.0 & \\
\hline
\end{tabular}

with their parents, $30 \%$ of the respondents which correspond to 30 students lived with a single parent, while another $30 \%$ of the respondents which correspond to 30 students do not live with their parents.

\section{Testing Hypotheses}

Research hypothesis 1: There is no significant effect of gender on the psychosocial challenges of adolescents in Lagos State.

From Table 4, the independent $\mathrm{t}$-test conducted revealed that $\mathrm{df}=98, \mathrm{~F}=$ 4.306 and $p>0.05$. This result showed that there is no statistically significant effect between the variables. Hence, we accept the null hypothesis. In other words, there is no significant effect of gender on the psychosocial challenges of adolescents. This implies that both male and female adolescents have psychosocial challenges.

Research hypothesis 2: There is no significant effect of age on the psychosocial challenges of adolescents in Lagos State.

Table 5 revealed that $\mathrm{F}(2,97)=1.726$ and that $p>0.05$. This result then showed that there is no statistically significant effect between the variables. Hence, we accept the null hypothesis. In other words, there is no significant effect of age on the psychosocial challenges of adolescents. This means that adolescents of all ages experienced one or more psychosocial challenges.

Research hypothesis 3: There is no significant effect of family type on the psychosocial challenges of adolescents In Lagos State. 
Table 4. Independent samples test of psychosocial challenges of adolescents based on gender.

\begin{tabular}{|c|c|c|c|c|c|c|c|c|c|c|}
\hline & & \multicolumn{2}{|c|}{$\begin{array}{l}\text { Levene's Test for } \\
\text { Equality of Variances }\end{array}$} & \multicolumn{7}{|c|}{ t-test for Equality of Means } \\
\hline & & \multirow[t]{2}{*}{$\mathrm{F}$} & \multirow[t]{2}{*}{ Sig. } & \multirow[t]{2}{*}{$\mathrm{t}$} & \multirow[t]{2}{*}{ Df } & \multirow[t]{2}{*}{$\begin{array}{c}\text { Sig. } \\
\text { (2-tailed) }\end{array}$} & \multirow[t]{2}{*}{$\begin{array}{c}\text { Mean } \\
\text { Difference }\end{array}$} & \multirow[t]{2}{*}{$\begin{array}{l}\text { Std. Error } \\
\text { Difference }\end{array}$} & \multicolumn{2}{|c|}{$\begin{array}{l}\text { 95\% Confidence } \\
\text { Interval of the } \\
\text { Difference }\end{array}$} \\
\hline & & & & & & & & & Lower & Upper \\
\hline \multirow{2}{*}{ Challenges } & Equal variances assumed & 4.306 & 0.041 & -0.033 & 98 & 0.974 & -0.19 & 5.761 & -11.622 & 11.241 \\
\hline & Equal variances not assumed & & & -0.031 & 48.632 & 0.975 & -0.19 & 6.097 & -12.446 & 12.065 \\
\hline
\end{tabular}

Table 5. ANOVA of psychosocial challenges of adolescents based on age.

\begin{tabular}{cccccc}
\hline & Sum of Squares & Df & Mean Square & F & Sig. \\
\hline Between Groups & 2347.018 & 2 & 1173.509 & 1.726 & 0.183 \\
Within Groups & $65,948.982$ & 97 & 679.886 & & \\
Total & $68,296.000$ & 99 & & & \\
\hline
\end{tabular}

Table 6 revealed that $\mathrm{F}(2,97)=674.500$ and that $p<0.05$. This result then showed that there is a statistically significant effect between the variables. Hence, we reject the null hypothesis. In other words, there is a significant effect of family type on the psychosocial challenges of adolescents. Figure 1 shows where the significant difference lies.

Figure 1 revealed that the mean scores of adolescents who lived with neither parent are very high. Hence, the significant difference lies in this group of adolescents.

\section{Discussion}

This study investigated the effect of demographic factors on the psychosocial challenges of adolescents in Lagos state. Implications for counselling. The first hypotheses state that there is no significant effect of gender on the psychosocial challenges of adolescents in Lagos State. This hypothesis is not rejected. The findings show that both male and female have psychosocial challenges. The reason for this is that during the period of adolescence, both male and female adolescents are undergoing this stressful period which may not account for any difference in their gender. However, males consistently have reported higher levels of externalizing behaviour in comparison to their female counterparts (Bongers, Koot, van der Ende, \& Verhulst, 2004). This also is at variance with the finding of Ahmad, Khalique, Khan, \& Amir (2007) on the prevalence of psychosocial problems among adolescents which state that male adolescents are more predisposed to psychosocial challenges. This could be a result of the fact that males are known for peer group influence which may contribute to higher psychosocial challenges in them. Moreover, Walsh (2004) and Roberts, Atkinson, \& Rosenblatt (1998) also attest that adolescent boys were found to be slightly higher than that of adolescents girls regarding their psychosocial problem (anxiety). 


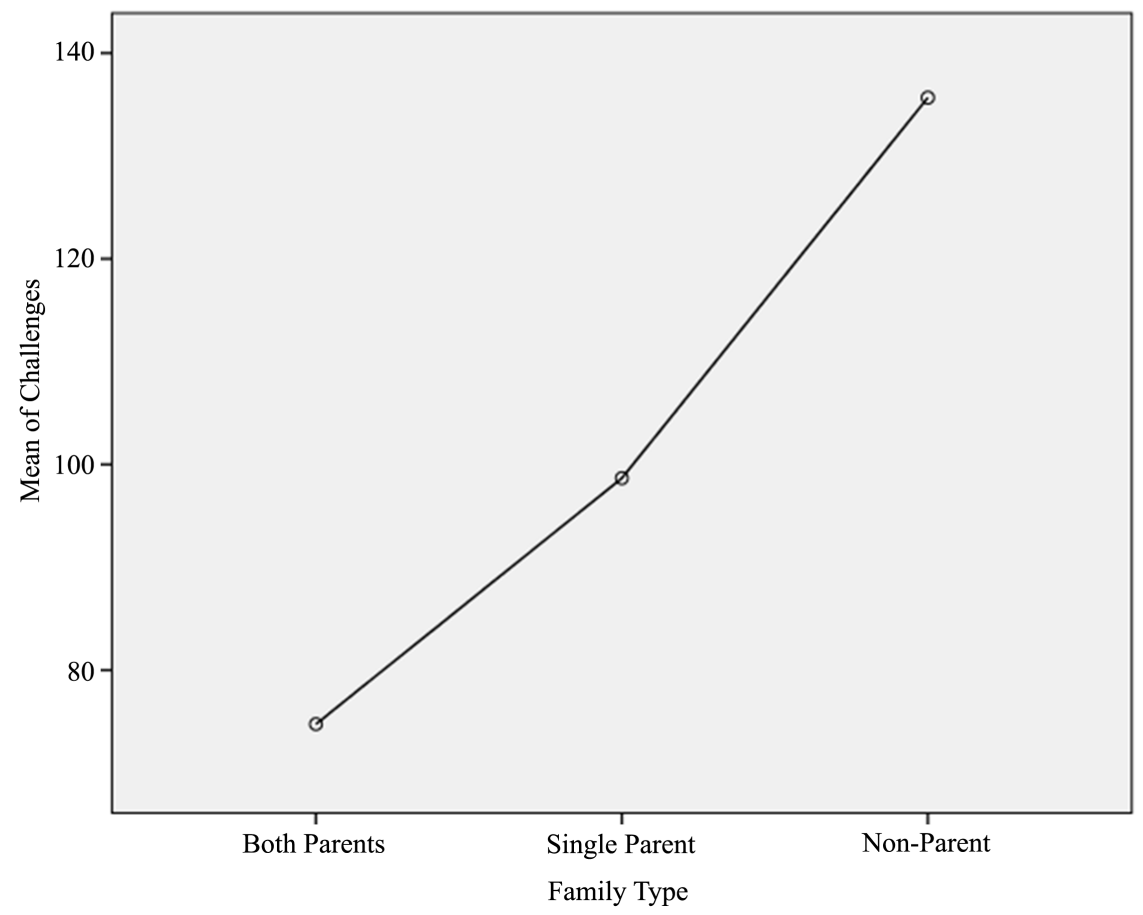

Figure 1. Psychosocial challenges of adolescents based on family type.

Table 6. ANOVA of psychosocial challenges of adolescents based on family type.

\begin{tabular}{cccccc}
\hline & Sum of Squares & Df & Mean Square & F & Sig. \\
\hline Between Groups & $63,715.167$ & 2 & $31,857.583$ & 674.590 & 0.000 \\
Within Groups & 4580.833 & 97 & 47.225 & & \\
Total & $68,296.000$ & 99 & & & \\
\hline
\end{tabular}

The second hypotheses state that there is no significant effect of age on the psychosocial challenges of adolescents. Therefore, the hypothesis was accepted. It is observed from the finding that adolescents of all ages experienced one or more psychosocial challenges. The reason could be that since the period of adolescence begins between the age range of 12 to 19 years, the adolescents may be experiencing these challenges at any year of the age. As such, it does not matter the age each adolescent fall into. The recent finding opposes the finding of Bista, Thapa, Sapkota, Singh, and Pokharel (2016) that psychosocial dysfunction was associated with the age groups 14 to 15 and 16 to 19 years. Similarly, the finding of Roberts, Atkinson, \& Rosenblatt (1998) found that adolescents among 12 years are having psychosocial challenges compare to the other ages.

The third hypotheses state that there is no significant effect of family type on the psychosocial challenges of adolescents. The hypothesis was rejected. From the findings, it is notable that adolescents who lived with neither parent are extremely high in terms of the problems they are confronted with. In other words, adolescents who lived with nonparents or guardians are confronted with one or more psychosocial challenges. The reasons are not farfetched. First, they are not 
their biological parents and as a result, the adolescents might be neglected and as such, may affect the way they feel, think, and behave in society. Secondly, these adolescents may not be showered with unconditional love and attention compared to adolescents living with both parents who will be given adequate attention and would be helped with their problems when they arise. Corcoran and Franklin (2002) oppose the finding that adolescents from intact families reported the lowest psychosocial problem (e.g. high self-esteem) as well as adolescents from single-parent families (either because of divorce or death of a parent).

\section{Conclusion}

This study brings out the effect of demographic factors and how they contribute to the psychosocial challenges of adolescents. It clearly shows that the family (parents) has a whole lot of impact on the shaping of the adolescents. This is because the family as an agent of socialization seems to show enormous concern, care, attention, and understanding towards the development and mental state of the adolescents.

\section{Counselling Implications}

A sizeable number of adolescents need support in coping with emotional, social, educational, and behavioural problems. That is, there should be an intervention strategy to prevent these problems in adolescents. Besides, School-based mental health services can handle the problem most effectively by providing help to those that are being confronted with these problems, especially at the earlier stage.

Furthermore, there is a need to have the role of counsellor being felt in every school system. With the presence of a counsellor, it will help to discover adolescents who have problems and those who are just developing problems so as to use appropriate therapies in curbing and reducing these problems. A community intervention may also be essential, and the school can become the base using innovative programs like student drama club, street plays, etc. thus educating the family as well as the community regarding the period of adolescence and some of the problems they may encounter in the process and how they (adolescents) can be managed to enable them to go through the transition process successfully.

\section{Acknowledgements}

The authors appreciate the school Principals for their support and understanding in carrying out the study. We show our sincere thanks to all students who participated in the study. We heartily show gratitude to Rev. Korede David for his statistical support. Lastly, appreciation of the management of Lagos State University for their unending support.

\section{Conflicts of Interest}

The authors declare no conflicts of interest regarding the publication of this paper. 


\section{References}

Ahmad, A., Khalique, N., Khan, Z., \& Amir, A. (2007). Prevalence of Psychosocial Problems among School-Going Male Adolescents. Indian Journal of Community Medicine, 32, 19-21. https://doi.org/10.4103/0970-0218.36836

Ajidaun, B. O. (2011). Impact of Psychosocial Factors on the Adolescents' Behaviour. Creative Education, 2, 398-401. https://doi.org/10.4236/ce.2011.24057

Bingham, C. (2006). Before Recognition, and After: The Educational Critique. Educational Theory, 56, 325-344. https://doi.org/10.1111/j.1741-5446.2006.00229.x

Bista, B., Thapa, P., Sapkota, D., Singh, S. B., \& Pokharel, P. K. (2016). Psychosocial Problems among Adolescents. An Exploratory Study in the Central Region of Nepal. Journal of Frontiers Public Health, 4, 158. https://doi.org/10.3389/fpubh.2016.00158

Bongers, I. L., Koot, H. M., van der Ende, J., \& Verhulst, F. C. (2004). Developmental Trajectories of Externalizing Behaviours in Childhood and Adolescence. The Netherlands, 75, 1523-37. https://doi.org/10.1111/j.1467-8624.2004.00755.x

Conger, R. D., \& Chao, W. (1996). Adolescent Depressed Mood. In J. W. Santrock (Ed.), Adolescence. New York: McGraw Hill.

Corcoran, J., \& Franklin, C. (2002). Multi-Systemic Risk Factors Predicting Depression, Self-Esteem, and Stress in Low SES and Culturally Diverse Adolescents. Journal of Human Behaviour in the Social Environment, 5, 61-76. https://doi.org/10.1300/J137v05n02_05

Hall, G. S. (1904). Adolescence: Its Psychology, Anthropology, Sociology, Sex, Crime, Religion, and Education. In Adolescence. New York: D. Appleton \& Co. https://doi.org/10.1037/10618-000

Kekkonen, V. K., Kivimaki, P., Valtonen, H., Tolmunen, T., Lehto, S. M., Hintikka, J., \& Laukkanen, E. (2015). Psychosocial Problems in Adolescents Associated with Frequent Health Care Use. Family Practice, 32, 305-310. https://doi.org/10.1093/fampra/cmu090

Kessler, R. C., Berglund, P., Demler, O., Jin, R., Merikangas, K. R., \& Walters, E. E. (2005). Lifetime Prevalence and Age of Onset Distributions of DSM-IV Disorders in the National Comorbidity Survey Replication. Archives of General Psychiatry, 62, 593-602. https://doi.org/10.1001/archpsyc.62.6.593

Pratt, H. D. (2003). Principles of Psychosocial Assessment in Adolescents. The Indian Journal of Pediatrics, 70, 775-780.

Roberts, R. E., Atkinson, C. C., \& Rosenblatt, A. (1998). Prevalence of Psychopathology among Children and Adolescents. The American Journal of Psychiatry, 155, 715-725.

https://doi.org/10.1007/BF02723793

Walsh, D. (2004). The Effect of Violent Video Game Habits on Adolescents Attitudes and Behaviours. Journal of Adolescence, 27, 5-22.

https://doi.org/10.1016/j.adolescence.2003.10.002

World Health Organization (2017). Maternal, Newborn, Child, and Adolescent Health. http://www.who.int

Young, J. (1997). Left Realist Criminology: Radical in Its Analysis, Realist in its Policy. In M. Maguire, R. Morgan, \& R. Reiner (Eds.), The Oxford Handbook of Criminology (2nd ed.). Oxford: Clarendon.

Younger, M., Warrington, M., \& Williams, J. (2010). The Gender Gap and Classroom Interactions: Reality and Rhetoric? British Journal of Sociology of Education, 20, 325-341. https://doi.org/10.1080/01425699995290 